\title{
O MERCADO dE INFORMAÇÃo BRASILEIRO
}

Marta Lígia Pomim Valentim

\begin{abstract}
Resumo
O mercado de informação brasileiro está em crescente desenvolvimento. A partir da segmentação do mercado de informação brasileiro, com base nos cinco anéis de Wurman, identificou-se a necessidade de uma maior visibilidade desse mercado, para que a sociedade brasileira realmente o conheça e use como qualquer outro segmento econômico. A visibilidade da área de informação como segmento econômico no país é fundamental para a sua própria consolidação.
\end{abstract}

\section{Palavras-Chave}

Mercado de Informação - Economia da Informação - Informação e Sociedade

O mercado de informação brasileiro está em desenvolvimento tal qual a situação do país. O discurso político-econômico brasileiro resgata, e muito, a necessidade de um país voltado para a educação e cultura de seu povo, alardeando a vital importância que essa atitude representa para a consolidação de um país.
No entanto, entre o discurso políticoeconômico e a prática político-econômica brasileira verifica-se um enorme fosso, de difícil transposição. O fosso, nesse caso, é representado pela falta de políticas claras e disseminadas, pela falta de recursos financeiros, pela falta de entendimento da importância da informação nesse processo e, talvez o mais representativo, o conservadorismo da iniciativa privada nesta área. 
Historicamente o Brasil é um país que não prioriza a educação e a cultura e, como conseqüência, também a área de informação, mesmo quando investe em ciência e tecnologia. Assim, suas ações e programas passam ao lado da questão da informação, não obstante seja ela insumo básico para o desenvolvimento de qualquer área, economicamente falando. Alem disso, a informação é elemento fundamental para formar, nos cidadãos, uma consciência crítica sobre as questões relativas ao país.

O mercado de informação brasileiro está-se formando e, para que ele se consolide, é necessário que a iniciativa privada veja claramente a cadeia produtiva da informação, invista neste nicho de mercado, como se investisse em fast-food, criando uma cultura de mercado e consumo de informação.

A demanda de informação no Brasil é totalmente reprimida. A grande maioria da população brasileira tem fome de comida, de escola, de saúde, isto é, ela carece dos requisitos mais básicos. Dessa forma, outras questões igualmente importantes, como a da informação, ficam em segundo plano, em terceiro, em quarto... A demanda existe e está reprimida exclusivamente por questões socioeconomicas.

Segundo Barreto, "a indústria da informação tem-se desenvolvido à margem das revoluções e do crescimento industrial (...) A indústria da informação organiza-se e diferencia-se pelo grau de organização

técnica e controle de seus estoques de informação, bem como pela manipulação política e econômica destes estoques" (1994, p.4).

A informação no Brasil, geralmente, é produzida, organizada e estocada através de seus produtores e utilizada por eles mesmos. A disponibilização desses estoques informacionais acontecem de forma elitista e provavelmente assim se pretende.

O mercado de informação brasileiro caracteriza-se como algo nebuloso, algo que não está claro, que não está definido, não está delineado. Identificar o mercado e os profissionais que atuam no mercado, de forma clara e precisa, faz-se necessário.

Inicialmente é necessário um delineamento claro e preciso do mercado de informação. Para tanto, parte-se do entendimento sobre mercado de informação, resgatando parcialmente os "cinco anéis" de Richard Wurman (1995, p.47-48), e introduzindo algumas modificações, da seguinte forma: a) mercado de informação cultural - abrangendo as áreas de artes, humanas e sociais; b) mercado de informação de mídias - abrangendo as áreas de comunicação e da ciência da informação; c) mercado de informação em ciência e tecnologia - abrangendo as duas áreas mencionadas, em toda a sua amplitude e, d) mercado de informação de referência - abrangendo todas as áreas do conhecimento humano, apresentado de forma referencial, de apoio

Inf.Inf., Londrina, v. 5, n. 1, p. 35-42, jan./jun. 2000 
ou cadastral.

Os mercados de informação citados, abastecem-se da produção de informação, nas diferentes áreas do conhecimento a que estão ligados, estabelecendo um ciclo vivo ou uma cadeia viva, que crescerá sempre que se alimentar das informações produzidas.

Entende-se que a cadeia produtiva de informação passa pela própria produção de informação, gerada nas diferentes áreas a que está ligada, consolidando desse modo, as informações geradas através de bancos de dados que realmente sejam disponibilizados democraticamente aos diversos segmentos da sociedade.

No setor de serviços, no Brasil, verifica-se que $52,03 \%$ das pessoas de 15 anos ou mais de idade, no ano de 1996, estavam distribuídas, atuando neste setor (IBGE, 1997, p.130-2).

O relatório sobre o desenvolvimento mundial, mais especificamente sobre a infra-estrutura para o desenvolvimento, do Banco Mundial, demonstra que no período de 1970 a 1980, o setor industrial tinha uma taxa média de crescimento de 9,4\% ao ano, maior que o setor de serviços, que tinha uma taxa média de crescimento de $8,0 \%$.

No entanto, a partir do ano de 1980 até 1992, houve uma inversão e, a partir de então, a taxa média de crescimento do setor de serviços foi de $3,4 \%$ ao ano. Esse dado é muito significativo, quando comparado à taxa média de crescimento do setor industrial, de apenas 1,4\% ao ano, no mesmo período, ou seja, menor que o de serviços (Banco Mundial, 1994, p.175).

O setor de serviços deve continuar crescendo e estar consolidado no terceiro milênio. O mercado de informação, um dos segmentos do setor de serviços, conseqüentemente também deve crescer e ser consolidado no mesmo ritmo.

No Brasil, o mercado de informação não é bem delineado, o que de certa forma prejudica o reconhecimento desse mesmo mercado, principalmente quando se pensa em investimento a longo prazo, para o crescimento do setor; prejudica igualmente o interesse da iniciativa privada não atuando de forma efetiva no setor. Portanto é necessário que este mercado seja segmentado. A Figura 1(apresentada na próxima página), de forma simplista, pretende demonstrar a segmentação do mercado de informação no Brasil.

O mercado de informação no Brasil tem tido uma influência significativa dos diversos setores governamentais, justamente porque estes setores têm sido grandes produtores, bem como disseminadores de informação. No entanto, o setor privado também é um grande produtor, porém não é um grande disseminador de informação.

Para a consolidação do mercado de informação no Brasil é necessário identifi- 
FIGURA 1

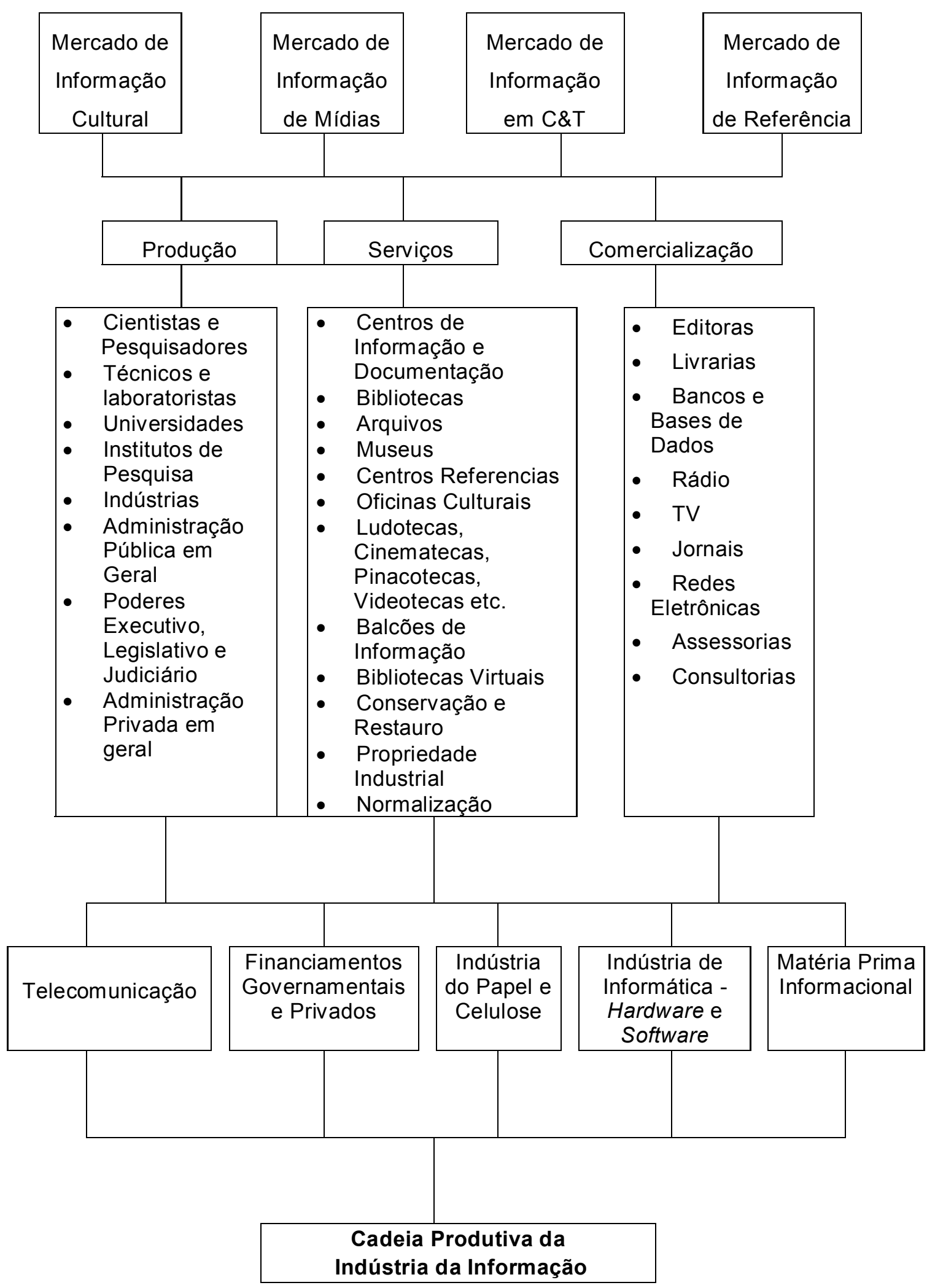

FIGURA 1 - SEGMENTAÇÃO DO MERCADO DE INFORMAÇÃO BRASILEIRO 
car os fatores (Figura 2) que podem afetar

sua consolidação e crescimento.

FIGURA 2

\begin{tabular}{|c|c|c|}
\hline FATORES ESTRUTURAIS & FATORES DE GESTÃO & FATORES SISTÊMICOS \\
\hline $\begin{array}{l}\text { 1. Baixo grau de } \\
\text { estabelecimento de } \\
\text { relaçães de parceria na } \\
\text { cadeia produtiva; } \\
\text { 2. Formação do profissional } \\
\text { da informação defasada } \\
\text { da demanda de mercado; } \\
\text { 3. Aparelhos institucionais da } \\
\text { área subtilizados; } \\
\text { 4. Situação socio-econômica } \\
\text { do país; } \\
\text { 5. Inexistência de } \\
\text { delineamento daro do } \\
\text { mercado de informação; } \\
\text { 6. Baixo grau de } \\
\text { conhecimento da iniciativa } \\
\text { privada sobre o mercado } \\
\text { de informação; } \\
\text { 7. Inexistência de } \\
\text { indicadores de avaliação, } \\
\text { de qualidade, de } \\
\text { desempenho e } \\
\text { competitividade para a } \\
\text { área; } \\
\text { 8. Baixo grau de } \\
\text { entendimento da } \\
\text { importância da } \\
\text { consolidação de dados no } \\
\text { país. }\end{array}$ & $\begin{array}{ll}\text { 1. } & \text { Dificuldades de } \\
\text { atualização completa das } \\
\text { tecnologias de } \\
\text { informação; } \\
\text { 2. Elevados custos de } \\
\text { manutenção dos sistemas; } \\
\text { 3. Baixa utilização de } \\
\text { recursos humanos com } \\
\text { formação universitária; } \\
\text { 4. Baixa disponibilização ou } \\
\text { descontinuidade de } \\
\text { políticas e programas de } \\
\text { fomento; } \\
\text { 5. Baixo grau de } \\
\text { investimentos na área } \\
\text { pela iniciativa privada; } \\
\text { 6. Marketing institucional e } \\
\text { profissional ainda } \\
\text { deficiente; } \\
\text { 7. } \text { Baixo grau de } \\
\text { conhecimento sobre os } \\
\text { programas } \\
\text { govemamentais de } \\
\text { fomento, tanto dos } \\
\text { profissionais da área } \\
\text { quanto da iniciativa } \\
\text { privada; } \\
\text { 8. Ausência de } \\
\text { financiamentos voltados } \\
\text { especificamente para a } \\
\text { área. }\end{array}$ & 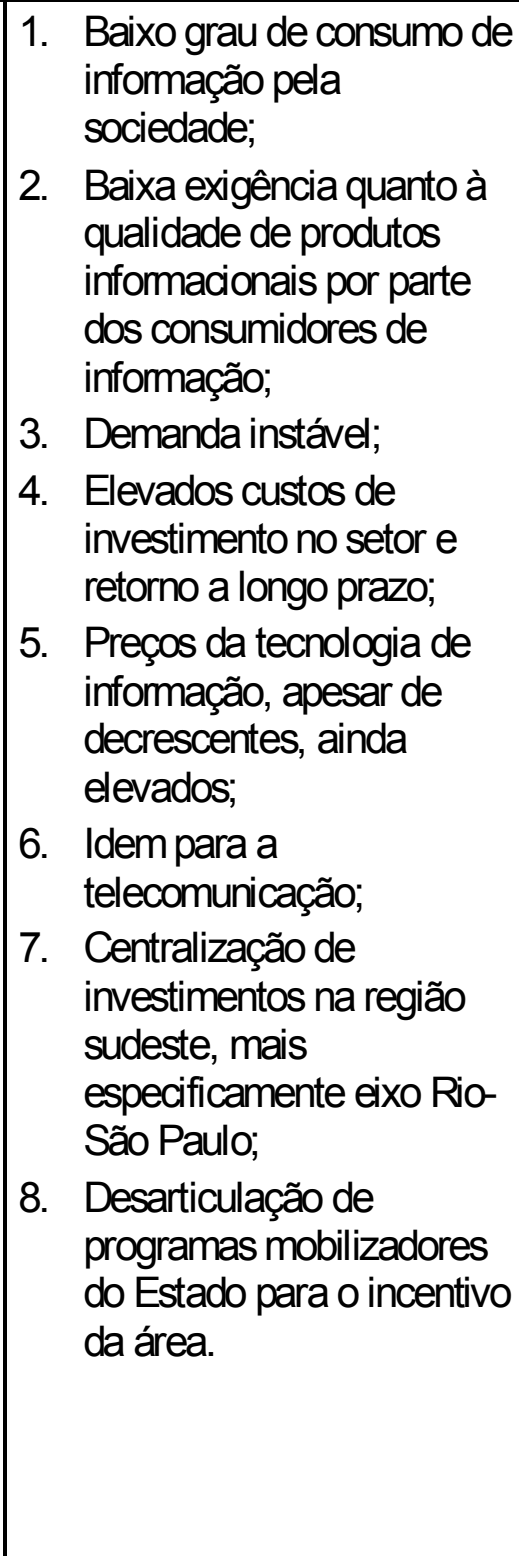 \\
\hline
\end{tabular}

FIGURA 2 - FATORES QUE AFETAM O MERCADO DE INFORMAÇÃO 
Porter afirma que os fatores de produção são geralmente "descritos em termos muito amplos, como terra, trabalho e capital, demasiado gerais para relacionar-se com a vantagem competitiva em indústrias estrategicamente distintas. Os fatores podem ser agrupados em várias categorias amplas: (...) Recursos de conhecimentos: o estoque que o país tem de conhecimentos científicos, técnicos e de mercado, relativos a bens e serviços. Os recursos de conhecimentos estão nas universidades, institutos governamentais e particulares de pesquisas, órgãos estatísticos governamentais, bibliografia de comércio e científica, relatórios de bancos de dados sobre pesquisas de mercado, associações comerciais e outras fontes..." (1993, p.91).

Além dos recursos de conhecimentos anteriormente citados por Porter, é necessário que as próprias indústrias brasileiras que desenvolvem $P \& D$, disponibilizem através de bancos de dados as informações de interesse público e/ou já dominadas publicamente, produzidas por elas através de relatórios técnicos, patentes, normas técnicas, papers entre outros.

A cadeia produtiva de informação no Brasil, bem como a consolidação das informações através de bancos de dados que realmente sejam acessados democraticamente, passam pela própria produção de informação, gerada pela indústria, pelo comércio, pela universidade etc. 


\section{Referências Bibliográficas}

BANCO MUNDIAL. Relatório sobre o desenvolvimento mundial 1994: infra-estrutura para o desenvolvimento. Rio de Janeiro : FGV, 1994. 267p.

BARRETO, A. de A. A questão da informação. São Paulo em Perspectiva, São Paulo, v. 8, n. 4, p. 3-8, out./dez. 1994.

IBGE. Brasil em números, Rio de Janeiro, v. 5, p. 1-317, 1997.

PASCHOAL, J. O. A., PASQUALINI, D. A. Competitividade e inovação tecnológica: um estudo do setor de revestimento cerâmico. São Paulo : FEA, 1997. 106p.

PORTER, M. E. A vantagem competitiva das nações. Rio de Janeiro : Campus, 1993. $897 p$.

WURMAN, R. S. Ansiedade de informação: como transformar informação em compreensão. 5.ed. São Paulo : Cultura Editores, 1995. $380 \mathrm{p}$.

\section{Marta Lígia Pomim Valentim Doutoranda da ECA/USP. Professora da Universidade Estadual de Londrina. Auto- ra do livro "O Custo da Informação Tecnológica".}

\section{Title}

The Brazilian Information Market

\section{Abstract}

The Brazilian information market is growing in a steady way. From the segmentation of the Brazilian information market, based on Wurman's five rings, the need for a broader visibility of such market is identified, so that the Brazilian society may get to know it and make use of it as it does of any other economical segment. The visibility of the information area as an economical segment in the country is essential for the country's own consolidation.

\section{Keywold}

Information Market; Information Economy; Information and Society.

\section{Titulo}

El Mercado de Información Brasileño

\section{Resumen}

El mercado de información brasileño está en creciente desarrollo. A partir de la segmentación del mercado de información brasileño y con base en los cinco anillos de Wurman, se ha identificado la necesidad de una mayor visibilidad de ese mercado, para que la sociedad brasileña realmente lo conozca y lo utilice como cualquier otro segmento económico. La visibilidad del área de información como segmento económico en el país es fundamental para su propia consolidación. 


\section{Palabras-Clave}

Mercado de Información; Economía de la

Información; Información y Sociedad.

Artigo recebido em: 30/04/98 